\title{
Simplified analytical method for the robustness assessment of precast reinforced concrete structural systems
}

\author{
Viktar Tur $^{1}$, Andrei Tur ${ }^{2}$, Aliaksandr Lizahub ${ }^{3}$ \\ ${ }^{1}$ Department of Building Structures; Faculty of Civil Engineering; \\ Bialystok University of Technology; 45E Wiejska Street, 15-034 Bialystok, Poland; \\ profturvic@gmail.com (DD 0000-0001-6046-1974 \\ ${ }^{2}$ Department of Building Structures; Faculty of Civil Engineering; Brest State Technical University; \\ 267 Moskovskaya, 224017 Brest, Belarus; \\ aturphd@gmail.com iD 0000-0002-9744-9044 \\ ${ }^{3}$ Department of Building Structures; Faculty of Civil Engineering; Brest State Technical University; \\ 267 Moskovskaya, 224017 Brest, Belarus; \\ p_332_14lizogub@mail.ru@iD 0000-0002-8896-0246
}

\begin{abstract}
The article presents the simplified implementation of alternative load path method based on the energy balance approach. This method should be used to check the global resistance of a damaged structural system after the occurrence of an accidental event. Basic assumptions of simplified analytical models for modelling resistance of horizontal ties in a damaged structural system, taking into account the membrane (chain) effects, were presented. An approach to modelling the dynamic resistance of a damaged structural system based on the energy balance method is described. Calculated dependencies for checking the robustness of a prefabricated multi-storey building with hollow-core slabs after the loss of the central column are proposed and considered using an example. On the considered example, a comparison of the required tie sections area with the dynamic resistance designed using the energy balance method (EBM) and according to the current standards, and a statistical assessment of the reliability of the load-bearing capacity models are carried out. In the end, a brief algorithm for the simplified calculation of the dynamic resistance of a damaged structural system is proposed.
\end{abstract}

Keywords: alternative path method, simplified analytical model, robustness, ties, energy balance method, membrane effect

\section{Introduction}

Resonant building disasters over the last century [1], [2] have shown that checking the robustness of damaged systems in accidental design situations should be considered as one of the most important stages of the design and detailing of the building structural elements . 
A structural system should fulfil the requirements regarding robustness at the stage of conceptual design, taking into account the use of various strategies for protection against progressive collapse.

It should be noted that in scientific and technical literature definitions of the term "robustness" are widely presented [1]-[6]. For example, fib Bulletin 43 [7] guidelines define structural robustness as the insensitivity of a structural system to local failure. In this context, insensitivity is understood as the state of a modified structural system, when damage to individual elements (the so-called key elements with respect to the system as a whole) causes only insignificant changes in its structural behaviour (its response). The ability of the system to redistribute additional action effects that appear after damaging the structure under the accidental actions is achieved. In this case, we expect to observe a ductile (not brittle) behaviour of structural components without global collapse mode in the structural system.

In the current standards [8]-[13], the requirement for robustness checking is implicit where an accidental situation is caused by events such as fires, explosions, impacts of vehicles on parts of the building, consequences of human errors made at various lifetime stages of the structure.

It should be noted that almost all known definitions of the term "robustness" [2] are based mainly on the phenomenon of disproportionate collapse, and only a few, for example [5], consider robustness as an aspect of the safety of a structural system. According to [13] "robustness is a specific aspect of structural safety that refers to the ability of system subject to accidental of exceptional loadings (such as fire, explosions, impact or consequences of human error) to sustain local damage to some structural components without experiencing a disproportionate degree of overall distress or collapse".

The draft new fib MC2020 develops provisions related to the assessment of the robustness of structural systems, which are based on the risk assessment format as presented in ISO 2394:2015 [14]. According to $f i b$ MC2020, structural robustness checks should include the following basic steps: (1) identification of the intended hazard $(H)$ or the list of hazards to which the structural system is likely to be exposed during a lifetime. At the same time, it should be taken into account that we may not identify some hazards at the designing stage (for example, terrorist and/or criminal attacks); (2) determination of the local resistance of an individual key element $(D)$; (3) determination of subsequent indirect damage to the system $(S)$ following direct local failure, also described as progressive collapse; (4) quantifying the values of direct $C_{\text {dir }}$ and indirect $C_{\text {ind }}$ consequences, including economic, social, environmental losses, as well as the cost of human life losses (human victims) in monetary terms according to ISO 2394:2015. Direct costs (damage) are usually localized because of the damage to individual structural components, while indirect losses are associated with the system functionality loss because of the implementation of direct losses. The total risk $R_{\text {tot }}$ associated with a system failure in an accidental design situation is calculated according to ISO 2394:2015.

The main strategies for the protection of structural systems from progressive collapse and the requirements for the robustness assessment of reinforced concrete structural systems are detailed in [1], [10], [12], [15]-[18]. In this article, we will consider only the alternative load path strategy (ALP) in more detail.

The combination of horizontal (internal and perimetric) and vertical ties placed in floor elements, columns and walls ensures the integrity of the structural system. In an accidental 
design situation, the system of ties is considered as the "second line of defence" of the structural system after the exhaustion of the flexural resistance of its elements.

When the internal support is removed in the floor elements, the arched effect, bending (beam) and membrane (chain) effects can be realized in succession (depending on the vertical displacement development for the different boundary conditions). If the slab deflection exceeds the critical value and the ties collapse or lose anchorage in adjacent spans, this will indicate that the limit state has been exceeded.

Compared to monolithic reinforced concrete structural systems, precast RC buildings are more sensitive to the effects of accidental actions. This is due to the presence of different types of butt joints that ensure integrity of the structural system and continuity of alternative load paths. At the same time, prefabricated systems distinguish between joints working in tension, compression, bending, torsion, and shear. When designing precast buildings, all requirements are taken into account, both the strategies for protection against progressive collapse and the checks of the structural system robustness .

In traditional prefabricated reinforced concrete systems, friction forces on the contact of elements, restraining deformations on supports (arch effect) and welded joints of embedded parts slightly increase the resistance of the system under the action of vertical (gravity) loads. However, this is not enough to ensure sufficient resistance of the structural system in accidental design situations. In this way, in the original precast RC-structural system, it is necessary to reserve enough ties that have the required continuity and ductility to ensure the integrity of the damaged system. The continuity of the tie elements provides resistance to an accidental combination of actions by mobilizing alternative load paths after the support has been removed. Ductility is the ability to obtain significant plastic bond elongation before rupture. Such property is important for redistributing forces and obtaining large deflections necessary for the realization of the chain (membrane) effect, as well as a measure that provides energy absorption (damping) during ?dynamic application of an accidental action after the vertical support loss.

In structural systems made of prefabricated reinforced concrete elements, all key elements whose failure can lead to the disproportionate collapse of the complete system should be identified at the stage of conceptual design. Therefore, at the first stage, it is recommended to analyse the local resistance of key elements, as it is performed, for example, in case of the panel buildings designing.

In a two-stage design, a structural system robustness check using non-linear static (NLS) or dynamic (NLD) models that consider the spatial work (3D) of the structural system is performed. Adequate modelling of ties is important when using computer software and it should be based on fairly simple and reasonable relationships. ("Make everything as simple as possible, but not simpler" - Albert Einstein).

The article presents simplified analytical solutions for the design of horizontal ties in precast hollow-core slabs floor which are obtained on the basis of the provisions of the energy balance approach [16]-[19]. Using the example of a real prefabricated floor, we compared the calculation results of the required parameters of horizontal ties designed according to the proposed method and calculation models included in the structural codes of various countries [8]-[13], [20]. It has been established that the ductility of ties is one of the basic parameters that should be controlled when calculating ties. 


\section{Analytical models for horizontal ties resistance}

\subsection{Membrane (chain) effects in a damaged structural system}

As shown above, redundancy of alternative load paths is considered as the main strategy for the protection of the structural system from progressive collapse. Alternative load paths in a damaged structural system are realized through "chain" (or "membrane") effects for floor slabs, cantilever and beam effects for precast walls, vertical suspension of walls and columns, diaphragm effect in the floor plane. When the chain (membrane) of the mechanism in the damaged structural system is implemented, all gravitational loading is detected due to reactions in the tensioned horizontal ties.

As follows from [2], until now there has been no consensus on the magnitude of the vertical deflection, after the exceeding of which chain effects are accounted for in the structural system resistance. It is generally accepted that this is a state when compressive axial forces become tensile, or a state in which the tie elements begin to actively detect tensile forces.

In RC frames, the beam-end-moment effect is initially implemented. Flexural plastic hinges are formed in the near support sections. After the exhaustion of their bending resistance at large deflections, chain (membrane) resistance mechanisms come into operation.

In accordance with the requirements of the standards [8], [10]-[13], [20], calculation of chain (membrane) forces in a deformed structural system is performed, as a rule, separately, without taking into account its bending behaviour during the formation of plastic hinges.

Chain (membrane) effects should be considered as the "second line of defence" of the structural system against progressive collapse if the damaged structural system is capable of mobilizing alternative loading paths.

\subsection{Basic assumptions of simplified analytical models}

For damaged structural systems, the resistance will depend on the dynamic effects during the transition to a deformed shape under an accidental action combination, as well as on the nonlinear behaviour of the connections. In the design, we should consider these effects in the calculation model. Bulletin 43 [7] proposed a simplified approach for such an analysis. The basic provisions of a simplified model for calculating modified systems with alternative load paths based on the application of the energy approach were developed in [16]-[19]. We apply the considered model for simplified analysis of the damaged load-bearing structural systems for which the global resistance depends on the resistance of the horizontal ties loaded by tension. However, the basic principles adopted in the described model are valid also for the analysis of another type of the collapse mechanism, where the plastic displacements are localized in connections. Considering the collapse mechanisms of the structural system, the development of analytical resistance models of horizontal tensile ties was carried out basing on the following assumptions:

1) we assume the key element to be removed from the structural system suddenly after the accidental action has been applied;

2) we assume that gravity force only loads the damaged system with the removed element. The accidental combination includes the characteristic value of the dead load and the quasi-permanent value of the imposed load. Basic rules for accidental load combinations when checking damaged structural systems are discussed in detail in [21], [22]; 
3) prefabricated elements under displacement of the system are assumed to be perfectly rigid bodies connected by deformable ties;

4) the global resistance of the damaged structure depends only on the resistance of some critical ties. During the development of the deflection in the damaged structural system, maximum forces arise in the ties;

5) at the stage when the support has suddenly been removed, these connections providing alternative load paths are assumed to be unstrained.

The gravity forces acting on the system are modelled by the resultant $Q=m g$ applied at the centre of gravity of the prefabricated elements. The actual position of the damaged system is determined by the generalized displacement $a_{\mathrm{q}}$ at the centre of gravity and a rotation $\theta$ (here, in the general case, $a_{\mathrm{qz}}$ is the vertical component of displacement). It is possible to establish simple geometric relationships between the vertical deflection of the system $a_{\mathrm{qz}}$ and the linear elongation $w_{\mathrm{i}}$ of the ductile joints following assumptions (2) and (4). The load-displacement relationship " $N-w_{\mathrm{i}}$ " should describe the nonlinear behaviour for each tie connection $i$ (see section 2.2).

\subsection{Modelling the dynamic resistance of a structural system based on energy balance: design equations}

According to assumption 5, immediately after the support is removed, the vertical displacements of the structural system are practically not limited because the ductile joints are unloaded. The system, when moving down, is under acceleration. The resultant tie forces in the damaged system can be taken as the system resistance $R$, which balances the gravity force acting in its centre of gravity. We can define resistance as static (quasi-static) or dynamic. According to the energy approach [16]-[19], the static resistance varies depending on the value of displacement and can be expressed by the resistance function $R_{\mathrm{stat}}\left(a_{\mathrm{qz}}\right)$ associated with the " $N-w$ " relationship for ductile ties in the joints of precast elements [7].

In the general case, the energy balance equation for the vertical displacement $a_{\mathrm{q}}$ and rotation $\theta$ of the moving system (see Fig. 1) can be written in the traditional form as:

$$
\frac{m}{2} \cdot\left(\frac{d a_{q}}{d t}\right)^{2}+\frac{I_{m}}{2} \cdot\left(\frac{d \theta}{d t}\right)^{2}=m \cdot g \cdot a_{q z}-\sum_{i=1}^{n} \int_{0}^{w_{i, \max }} N_{i}\left(w_{i}\right) d w_{i}
$$

where $I_{\mathrm{m}}$ is the mass moment of inertia.

The first term on the right-hand side of equation (1) describes the potential energy, and the last term is the absorbed strain energy of the tie. The two terms on the left-hand side of this equation describe the kinetic energy because of the displacement and rotation, respectively. To obtain a deformed state of equilibrium, the motion of the system must stop. At the downward position, the kinetic energy of the structural system has the value $W_{\mathrm{k}}=0$. In this case, we assume that the maximum vertical deflection $a_{\mathrm{qz}, \max }$ of the gravity centre of the damaged part in the structural system and of the tie linear displacements $w_{\mathrm{i}}$ is reached. The equilibrium equation for the deformed state of a system with single-degree-of-freedom (SDOF) in the first half-period of oscillations can be written in the traditional way (Eq. 2):

$$
Q \cdot a_{q z, \max }=\sum_{i=1}^{n} \int_{0}^{w_{i, \max }} N_{i}\left(w_{i}\right) d w_{i}
$$

where $a_{\mathrm{qz}, \max }$ is the maximum vertical deflection in the point, where the driving force $Q$ is applied, when the downward motion stops; $w_{\mathrm{i} \text {,max }}$ is the horizontal displacement of the $i$-th connections. 
According to [7], the strain energy capacity of the tie can be obtained from the relationship " $N-w$ " as follows:

$$
\xi(w)=\frac{W_{\text {int }}(w)}{N_{u} \cdot w}=\frac{\int_{0}^{w} N(w) d w}{N_{u} \cdot w}
$$

Therefore, Eq. 2 expressing the energy balance of the deformed system can be written as:

$$
Q \cdot a_{q z, \max }=\sum_{i=1}^{n} \xi_{i}\left(w_{i, \max }\right) \cdot N_{i, u} \cdot w_{i, \max }
$$

At the stage when the motion stops at the downward position, the system is not necessarily in equilibrium. Therefore, besides Eq. 4, the following inequality should be met:

$$
R_{\text {stat }}\left(a_{q z, \max }\right) \geq m \cdot g
$$

If inequality (5) is not met, the accepted value of $a_{\mathrm{qz}, \max }$ is not correct, since before it is reached, the tie elements are broken. The process of successive destruction of the tie elements with an increasing displacement of the modified system is called the zipper-type mode.

The conditions of the equilibrium of forces in the deformed state for the proposed collapse mechanism are checked using Eq. 4 and Eq. 5. The dynamic resistance of the damaged system is based on the resistance of horizontal ties to the maximum driving force $Q=m g$ after a sudden removal of the column.

As follows from Eq. 4, the dynamic resistance $R_{\mathrm{dyn}}\left(a_{\mathrm{qz}, \mathrm{max}}\right)$ depends on the maximum vertical deflection $a_{\mathrm{q} z \text { max }}$, which is chosen to consider 1) the availability of free space for the downward movement of the system (for example, according to [7] and [11], it is the distance to the underlying floor) and 2) the ductility of the ties.

A quantitative assessment of the uncertainties of the proposed simplified method based on energy balance, in comparison with the direct nonlinear dynamic analysis, is considered in [16]-[19], in particular in the most recent of them [23]. In [23], it was noted that instead of the cumbersome nonlinear dynamic analysis (NLD), which contains a number of uncertainties (for example load history, damping coefficient, etc.), the method based on energy balance (EBM) is a promising approach for determining the maximum dynamic response of the structure. Despite some errors adopted in the estimation, authors [23] show that the method based on the energy balance is quite accurate and effective both 1) in implementing the bending mechanism (the formation of plastic hinges at small deformations), and 2) at the stage of the membrane (chain) effect implementation in ties that detect tension (the stage of large displacements). Studies [23] show that the model describing the uncertainty (modelling error) of the energy balance method (EBM) compared to nonlinear dynamic analysis (NLD) describes it well using a lognormal distribution with the following statistical parameters LN $(0.95 ; 0.20)$. (It should be noted that there is a certain amount of slyness here: the finite element model should be tested basing on classical laws, and not vice versa).

\section{Prefabricated building with hollow-core slabs}

\subsection{Static and dynamic resistance}

As shown above (see Eqs. 2-4), the resistance of a damaged system with alternative loading paths almost directly depends on the ductility of the tie connections. 
Let us consider a prefabricated floor with hollow-core slabs of equal spans. The internal support of the continuous girder is removed under accidental action. When the support is removed, a longitudinal strip of the prefabricated floor together with the ties forms an alternative load-bearing bridging system. In accordance with the formulated assumptions (see Section 2.2), in the ultimate state prefabricated floor elements are considered as rigid bodies connected by ductile ties.

After the sudden removal of the mid-column of the continuous girder, the prefabricated slabs rotate at the adjacent supports and move in the horizontal direction.

As follows from [2] and [7], the resistance model considers a longitudinal strip of prefabricated floor elements (for example, hollow-core slabs). In this simplified model, the resistance in the transverse direction, arch, and beam effects in the longitudinal direction are neglected and are not taken into account.

We assume that the horizontal ties of the system have the same mechanical characteristics; therefore, for any state of deflection, the three ties have the same tensile force and the same elongations, because the characteristic load-deflection $N$-w relationships for each tie are the same. For each precast floor element, the resultant $Q$, which is assumed to be placed in the gravity centre of the element, represents the self-weight and other permanent loads. The deformed state is described using the deflection $a_{\mathrm{qz}}$ of the driving force [7] (see Fig. 1).

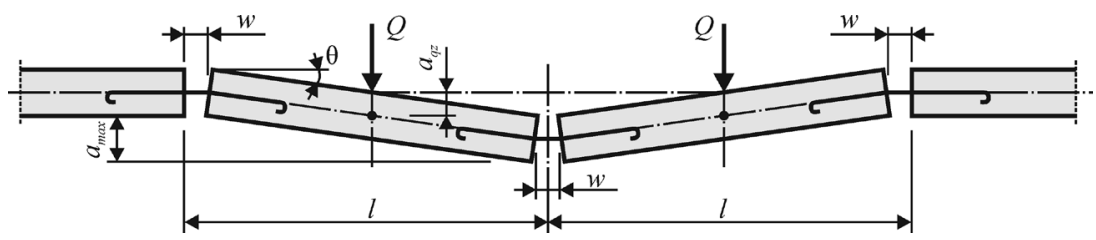

Fig. 1. Deformed scheme of prefabricated floor for catenary (chain) forces calculation. Source: own study

From the conditions of the static equilibrium of the system in a deformed state, we can write:

$$
Q \cdot \frac{l}{2}=N(w) \cdot 2 \cdot a_{q z}
$$

For the certain displacements $w$ of the horizontal ties, the vertical deflection $a_{\mathrm{qz}}$ can be calculated directly from the deformed geometric scheme (see Fig. 1) as:

$$
a_{q z}=\frac{\sqrt{3 \cdot l \cdot w}}{2}
$$

where $l$ is the length of the prefabricated elements.

Considering Eq. 7, static resistance is expressed as:

$$
R_{\max }\left(a_{q z, \max }\right)=2 \cdot N(w) \cdot \sqrt{\frac{3 \cdot w}{l}}
$$

The maximum value of the static resistance is associated with the maximum displacement $a_{\mathrm{qz}, \max }$, at which the downward movement of the system must be stopped and which is determined by the formula:

$$
R_{\max }\left(a_{q z, \max }\right)=2 \cdot N_{u} \cdot \sqrt{\frac{3 \cdot w_{\text {max }}}{l}}
$$


We can express the energy equilibrium condition for the doubled span system as:

$$
2 Q \cdot a_{q z, \max }=3 \xi\left(w_{\max }\right) \cdot N_{u} \cdot w_{\max }
$$

By introducing Eq. 7 and Eq. 9 into Eq. 10, we obtain the dynamic resistance as:

$$
R_{d y n}\left(a_{q z, \max }\right)=\frac{1}{2} \xi\left(w_{\max }\right) \cdot R_{\max }
$$

As stated in [2], even if the tie will have an ideally plastic response, the static response of the system based on the chain (catenary) actions increases almost linearly with increasing displacement, therefore Eq. 11 uses a factor of $1 / 2$.

\subsection{Modelling of the tie elements. " $N$-w" relationship for reinforcing bar}

The " $N-w$ " relationship relates the tensile force $N$ in the tie connection and its end displacement $w$ (local end-slip displacement). To obtain the " $N-w$ " diagram, it is necessary to have an adequate local bond-slip relationship " $\tau-s$ " (Fig. 2). Basing on extensive experimental research [24], including our own, we adopted the dependence in accordance with [8] and [13].

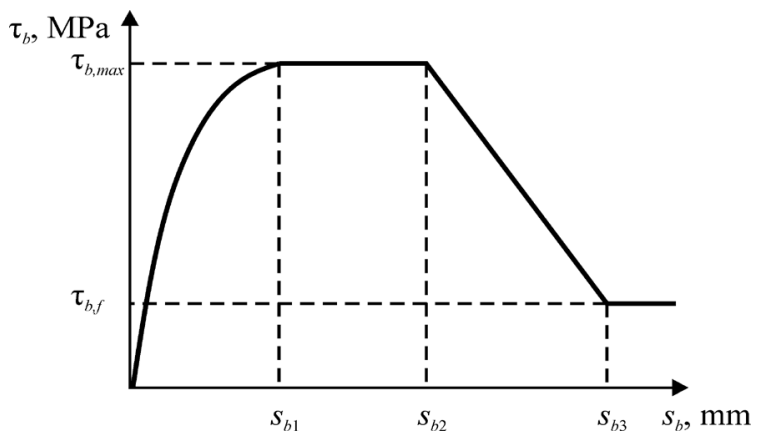

Fig. 2. Analytical bond stress-slip relationship Source: [8], [13]

The advantage of the relationship (Fig. 2) is the applicability for both ribbed and plain bars, as well as an almost complete range of concrete classes, including high-strength ones [8], [13], [24]. The bond-slip behaviour for reinforcement bars is modelled according to [13].

According to [24], for the " $N-w$ " diagram development, it is necessary to determine (a) the transmission length $l_{\mathrm{t}}$ and (b) the strain $\varepsilon_{\mathrm{s}}(x)$ and $\varepsilon_{\mathrm{ct}}(x)$ distribution along this length.

In the general case, the transmission zone length increases with increasing tensile stress. In this case, for a steel bar embedded in concrete, the following cases are possible: (1) the length of the transmission zone is shorter or equal to the anchorage length; (2) the transmission zone length is greater than the anchorage length. It should be noted that for continuous tie elements passing through the overlap case (1) is usually valid.

According to [8] and [13], for monotonic loading the reference value of $\tau_{\mathrm{b}}$ of the bond stresses between concrete and the reinforcing bar can be calculated as follows:

$$
\tau_{b}=\tau_{b, \max } \cdot s_{b}^{0.4}
$$

where $\tau_{\mathrm{b} \text {,max }}$ is the maximum bond-shear stresses between concrete and the reinforcing bar in accordance with [8]; $s_{\mathrm{b}}$ is the current value of the relative slip displacement of the reinforcing bar in concrete. 
If the anchorage length is greater than the transmission length, to determine the slip displacement we assume to consider the concrete element rigid in relation to the reinforcing bar. Such an assumption gives a slight overestimation of the designed value of the end slip. According to works [7] and [24], the relation (13) is valid if the following requirements are satisfied: 1) the steel bar works in an elastic stage; 2) the net end-slip is less than $1.0 \mathrm{~mm}$ :

$$
\begin{aligned}
& w_{\text {end }}=0.288 \cdot\left(\frac{\varnothing \cdot \sigma_{s}^{2}}{\tau_{b, \max } \cdot E_{s}}\right)^{0.714}+\frac{\sigma_{s}}{E_{s}} \cdot 2 \cdot \varnothing \\
& \text { where } \tau_{b, \max }=2.5 \sqrt{f_{c d}} \text { for "good" bond conditions; } \\
& \tau_{b, \max }=1.25 \sqrt{f_{c d}} \text { for "all other" bond conditions; }
\end{aligned}
$$

$\varnothing$ is the bar diameter, in [mm].

In Eq. 13, the first term on the right-hand side describes the end-slip displacement caused by bond stresses along that part of the transmission length where bond stresses appear, here defined as the "net end-slip" $s_{\text {end,net }}$ :

$$
s_{\text {end }, \text { net }}=0.288 \cdot\left(\frac{\varnothing \cdot \sigma_{s}^{2}}{\tau_{b, \max } \cdot E_{s}}\right)^{0.714}
$$

The last term of Eq. 13 considers the effect of local concrete failure near the free end over a length of approximately $2 \varnothing$.

The relationship between stress $\sigma_{\mathrm{s}}$ and a given end-slip displacement can be rewritten from Eq. 15 as follows:

$$
\begin{gathered}
\sigma_{s}=2.39 \cdot \sqrt{\frac{\tau_{b, \max } \cdot E_{s}}{\varnothing} \cdot s_{\text {end, net }}^{1.4}} \\
\text { where } s_{\text {end, net }}=w_{\text {end }}-\frac{\sigma_{s}}{E_{s}} \cdot 2 \cdot \varnothing
\end{gathered}
$$

The transmission length according to works [7] and [24] is calculated as:

$$
l_{t}=0.583 \cdot \frac{\varnothing \cdot \sigma_{s}}{\tau_{b, \max } \cdot s_{\text {end }, \text { net }}^{0.4}}+2 \cdot \varnothing
$$

When yielding in steel reinforcement starts, the end-slip $w_{\text {end,y }}$ and the transmission length $l_{\mathrm{t}, \mathrm{y}}$ can be obtained by inserting $\sigma_{\mathrm{s}}=f_{\mathrm{yd}}$ into Eq. 16 and Eq. 18. In the general case, the relationship " $N-w_{\text {end }}$ " is nonlinear before steel yielding is reached. However, the pull-out stiffness of the joint $k_{\mathrm{a}}\left(w_{\text {end }}\right)$ is generally defined as a secant at point $N\left(w_{\text {end }}\right)$ :

$$
k_{a}\left(w_{\text {end }}\right)=\frac{N\left(w_{\text {end }}\right)}{w_{\text {end }}}
$$

As the first approximation, we can obtain the value of the connection pull-out stiffness based on the stiffness it reached just before yielding:

$$
k_{a}=\frac{N_{y}}{w_{\text {end }, y}}
$$

where $N_{\mathrm{y}}$ is the force corresponding to the steel yielding in the tie connection; $w_{\text {end,y }}$ is the end-slip corresponding to $\sigma_{\mathrm{s}}=f_{\mathrm{yd}}$. 
It should be noted that Eq. 19 underestimates the stiffness for loads less than $N_{\mathrm{y}}$. A more accurate value of the axial stiffness is calculated by Eq. 20 for a given loading range or the end-slip.

According to [7], the "plastic zone length" is defined as the part of the transmission length where the reinforcement bar has reached yielding. Within the "plastic zone length", the bond-shear stress decreases due to steel yielding to [24].

If the anchorage length of the reinforcement bar in the concrete body is sufficient, the maximum value of the "plastic zone length" along the transmission length can be calculated accounting for the fact that the reinforcing steel reaches rupture tensile strength $f_{\mathrm{u}}$. Along the "plastic zone" length, the tensile stress in reinforcement increases from the value of yield strength $f_{\mathrm{y}}$ to the value of the ultimate tensile strength $f_{\text {ud }}$ at the loaded end of the bar.

The ultimate value of the plastic zone length can be calculated according to [24] as:

$$
l_{t, p l}=\left(\frac{f_{u d}-f_{y d}}{\tau_{b m, p l}}\right) \cdot \frac{\varnothing}{4}
$$

where $\tau_{\mathrm{bm}, \mathrm{pl}}$ is the average value of bond-shear stress, calculated by Eq. 22 .

To calculate the average shear-bond stress for ribbed bars of ductile type (classes B and $\mathrm{C}$ according to [8] determined as "high ductility") in [7], [24], the following formula has been proposed:

$$
\tau_{b m, p l}=0.27 \tau_{b, \max }
$$

where $\tau_{\mathrm{b}, \max }$ is determined by Eq. 14a or Eq. 14b, depending on the bond conditions.

The ultimate end-slip of the tie bar can be calculated as follows:

$$
w_{\text {end }, u}=l_{t, p l} \cdot \varepsilon_{\text {sm, } p l}+w_{\text {end }, y}
$$

where $\varepsilon_{\mathrm{sm}, \mathrm{pl}}$ is the average strain of the reinforcing bar along the plastic zone length, and according to [7] it can be estimated as $\varepsilon_{\mathrm{sm}, \mathrm{pl}}=0.5 \varepsilon_{\mathrm{su}}$.

As follows from Eq. 23, with an increase of the plastic zone length $l_{\mathrm{t}, \mathrm{p}}$. the ultimate displacement of the tie increases. An idealized three-line " $N$-w" relationship shown in Fig. 3 can be proposed, basing on the recommendations of [7].

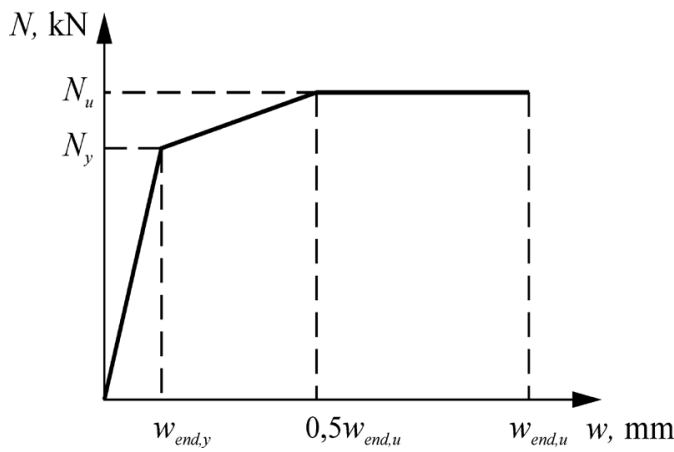

Fig. 3. Idealized " $N-w$ " relationship. Source: [7], [24] 


\section{Example of checking the robustness of precast multi-storey building}

\subsection{Structural system description, input data for analysis}

As an example, we will consider the structural system of an 18-storey building, the plan of which is shown in Fig. 4. In the considered structural system, monolithic (cast-in-place) columns with a section of $300 \times 300 \mathrm{~mm}$ (along axes 2,7) and prefabricated panel walls (along axes $1,4,8)$ are used as supporting vertical elements. Floors are made of prefabricated hollowcore slabs $(1.2 \times 6.0 \times 0.22 \mathrm{~m})$ with modification in the support nodes. The slabs are supported on prefabricated girders with a height of $0.26 \mathrm{~m}$ (see Fig. 4). At the stage of preliminary analysis and design, an integrated system of horizontal and vertical ties under the requirements of [8] and $[10]$ was designed.

In accordance with the input data, the following characteristic values of actions were adopted for the design: (1) dead load of floor slabs $g_{\mathrm{k} 1}=3.05 \mathrm{kPa}$; (2) dead load of the floor finishing $g_{\mathrm{k} 2}=0.6 \mathrm{kPa}$; (3) imposed load $q_{\mathrm{k}}=1.5 \mathrm{kPa}$. An accidental load combination is taken as:

$p_{\mathrm{A}}=g_{\mathrm{k} 1}+g_{\mathrm{k} 2}+\psi_{2} \cdot q_{\mathrm{k}}=3.05+0.6+0.3 \cdot 1.5=4.1 \mathrm{kPa}$.

According to the proposed analytical model, we check the robustness of the structural system taking into account the chain (membrane) effects.

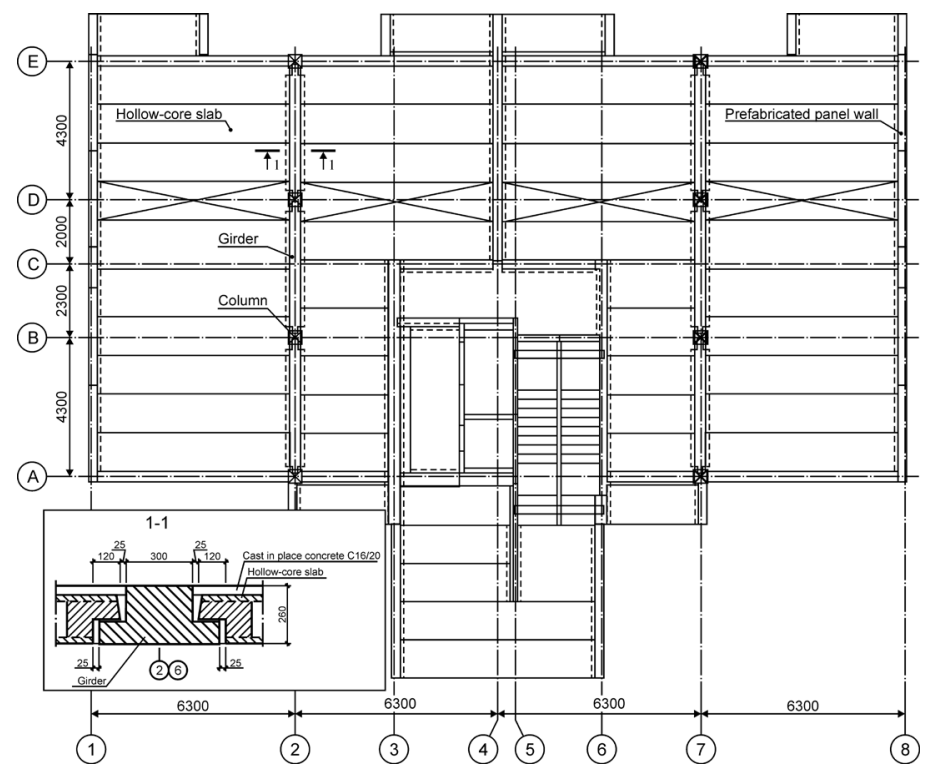

Fig. 4. The first floor of an analysed 18-storey prefabricated framed building. Source: own study

Within the framework of the approaches in the current codes and guidelines [8]-[12], the resistance of precast floor slabs in one direction and resistance of prefabricated girders in the other (transverse) direction are considered separately. To determine the required cross-sectional areas of horizontal ties in girders and slabs, the principle of compatibility of vertical displacements 
at the point of the column removal is used. In accordance with this principle (the principle of compatibility), the force-deformation connection parameters of the ties in the beams and slabs are determined in the condition of equality of displacements: $a_{\max , \mathrm{p}}=a_{\text {max, }}$ (here, $a_{\max , \mathrm{p}}$ and $a_{\max , \mathrm{b}}$ are the maximum deflection of slabs and girders at the remote element, respectively).

\subsection{Modelling of the horizontal tie}

Plain bars Ø28S240, which have significant plastic deformability, are accepted as tie connections. The following reinforcement steel properties are taken: $f_{\mathrm{yk}}=240 \mathrm{MPa} ;\left(f_{\mathrm{u}} / f_{\mathrm{y}}\right)_{\mathrm{k}}=1.3$; $E_{\mathrm{s}}=200 \mathrm{GPa} ; \varepsilon_{\text {suk }}=1.5 \cdot 10^{-2} ; A_{\mathrm{s}}=616 \mathrm{~mm}^{2}$. It is assumed that the tie bar is anchored in confined concrete of compressive strength class $\mathrm{C} 20 / 25\left(f_{\mathrm{ck}}=20 \mathrm{MPa} ; f_{\mathrm{cm}}=20+8=28 \mathrm{MPa}\right)$, "good" bond conditions. In Tab. 1, the values of the main parametric points of the " $N-w$ " relationship (Fig. 3) for tie connections are presented, which are calculated basing on the proposed end-slip approach.

Table 1. " $N-w "$ relationship basic points for plain bars Ø28S240. Source: own study

\begin{tabular}{|c|c|c|c|c|c|}
\hline \multirow{2}{*}{ № } & \multirow{2}{*}{ Reinforcement } & \multicolumn{4}{|c|}{ Parameters for " $N-w$ " diagram } \\
\hline & & $N_{\mathrm{y}}, \mathrm{kN}$ & $N_{\mathrm{u}}, \mathrm{kN}$ & $w_{\text {end,y }}, \mathrm{mm}$ & $w_{\text {end,u }}, \mathrm{mm}$ \\
\hline 1 & $2 \varnothing 28 \mathrm{~S} 240$ & 295.68 & 384.38 & 0.658 & 28.94 \\
\hline 2 & $4 \varnothing 28 S 240$ & 591.40 & 768.76 & 0.658 & 28.94 \\
\hline
\end{tabular}

Note: general view of the " $N$-w" diagram see Fig. 3.

\subsection{Analytical solution for ties sections area}

Let us consider a strip of girders along axis 2 (Fig. 4). We conclude that the internal tie connections in the direction of axis 2 are concentrated in prefabricated girders. The girders are loaded with an accidental loads combination as follows: $Q=4.1 \times 6.0 \times 4.0=98.4 \mathrm{kN}$. The girders have a loop connection at the column (2Ø25S500) and have additionally reserved horizontal tie connections (4Ø28S240). The deflection of the middle joint (at the joint with the removed column) should not exceed $2.3 \mathrm{~m}$ (free floor space). In Tab. 2, the main design parameters and the results of robustness checking are presented.

Basing on the accepted concept of the deflection compatibility, we will show how to determine the required cross-sectional area of the tie connections for a given type of reinforcement (S240).

Basing on the results from Table 2, the required ultimate force to break the bar can be calculated from Eq. 9 as:

$$
N_{u}=\frac{R_{\max }}{2 \cdot \sqrt{\frac{3 \cdot w_{\max }}{6.0}}}=\frac{60.86}{2 \cdot \sqrt{\frac{3 \cdot 0.0206}{6.0}}}=299.8 \mathrm{kN},
$$

where $R_{\max }=\frac{2 \cdot R_{d y n}}{\xi\left(w_{\max }\right)}=\frac{2 \cdot 29,52}{0,97}=60,86 \mathrm{kN}$.

Since $2 \varnothing 28 \mathrm{~S} 240 N_{\mathrm{u}}=384 \mathrm{kN}>299.8 \mathrm{kN}$, the required reinforcing bar area equals:

$$
A_{s, \text { req }}=\frac{N_{u}}{1.3 \cdot f_{y k}}=\frac{299.8 \cdot 10^{3}}{1.3 \cdot 240}=960.9 \mathrm{~mm}^{2} \text {; }
$$

we accept $2 \varnothing 25 \mathrm{~S} 240\left(A_{\mathrm{s}}=982 \mathrm{~mm}^{2}\right)$. 
Table 2. Robustness checking results for an analysed precast building (by EBM). Source: own study

\begin{tabular}{|c|c|c|c|c|}
\hline Calc. step & Design Parameter & Reference & Value & Units \\
\hline \multicolumn{5}{|c|}{ Girders $(l=4.3 \mathrm{~m})$} \\
\hline 1 & $w_{\max }$ & Tab. 1 & 0.02894 & $\mathrm{~m}$ \\
\hline 2 & $a_{\mathrm{max}, \mathrm{b}}=2 a_{\mathrm{qz}, \max }$ & Eq. 6 & 0.61 & $\mathrm{~m}$ \\
\hline 3 & $R_{\max }$ & Eq. 9 & 218.47 & $\mathrm{kN}$ \\
\hline 4 & $R_{\mathrm{dyn}}$ & Eq. 11 & 218.47 & $\mathrm{kN}$ \\
\hline 5 & $R_{\mathrm{dyn}}>Q$ & Eq. 5 & $105.8>98.4$ & \\
\hline \multicolumn{5}{|c|}{ Hollow-core slabs $(l=6.3 \mathrm{~m})$} \\
\hline 6 & $a_{\max , \mathrm{s}}=a_{\mathrm{max}, \mathrm{b}}$ & see note ${ }^{(1)}$ & 0.61 & $\mathrm{~m}$ \\
\hline 7 & $w_{\max }$ & Eq. 6 & 0.0206 & $\mathrm{~m}$ \\
\hline 8 & $R_{\max }$ & Eq. 9 & 77.94 & $\mathrm{kN}$ \\
\hline 9 & $R_{\mathrm{dyn}}$ & Eq. 11 & 37.80 & $\mathrm{kN}$ \\
\hline 10 & $R_{\mathrm{dyn}}>Q$ & Eq. 5 & $37.8>29.52$ & \\
\hline
\end{tabular}

Notes:

1) based on the compatibility hypothesis $a_{\mathrm{max}, \mathrm{s}}=a_{\mathrm{max}, \mathrm{b}}$.

\subsection{Comparison of the required tie sections area and dynamic resistance designed using energy balance method (EBM) and according to current standards}

At the first stage, we verified the proposed model based on the results of our own investigations [25] obtained by testing span-to-span hollow-core slab fragments under uniformly distributed load and sudden support removal (see Fig. 5). It was found that the obtained experimental results are in good agreement with the calculation based on EBM.
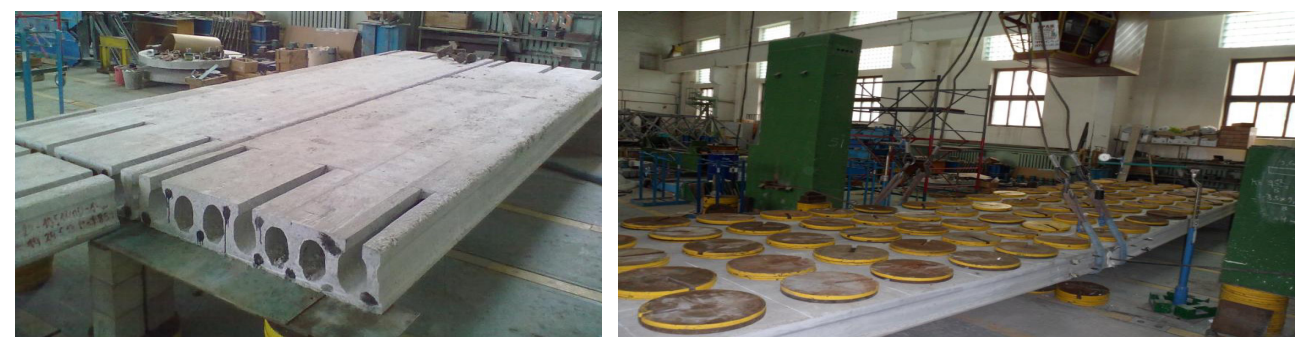

Fig. 5. Experimental investigation of hollow-core slab fragment. Source: [25]

Let us compare now the calculation results obtained using the proposed model (EBM) and the models included in the codes and standards of various countries. In Tab. 3, the results of calculating the required cross-sectional area of horizontal tie connections according to the current standards are given.

The analysis of standards [8], [10]-[12] shows that all the design models for the calculation of the chain (membrane) force presented in Tab. 3 are based on the equations which are obtained from the condition of static equilibrium of the deflected system at the maximum vertical displacement:

$$
T_{j}=(1+\alpha) \cdot \frac{\left(g_{k}+\psi_{i} \cdot q_{k}\right) \cdot l_{b}^{2}}{2 \cdot \delta_{s}}
$$


where $\delta_{\mathrm{s}}$ is the vertical displacement of the joint with the removed element.

In work [2] it is shown that the design model of [10] and [11] is based on the following formula for the determination of the vertical displacement:

$$
\delta_{s}=18.75 \cdot(1+\alpha) \cdot \frac{l_{b}}{T_{j}}
$$

Table 3. Designing horizontal ties according to current standards. Source: own study

\begin{tabular}{|c|c|c|c|c|c|c|c|}
\hline \multirow{2}{*}{ № } & \multirow{2}{*}{ Reference } & \multirow{2}{*}{ Expression } & \multicolumn{2}{|c|}{ Tie Force, $T_{\mathrm{j}}$} & \multirow{2}{*}{$\begin{array}{l}a_{\max }^{(2)} \\
\mathrm{m}\end{array}$} & \multirow[b]{2}{*}{$\delta_{\mathrm{s}}$} & \multirow{2}{*}{$\begin{array}{l}\text { Reinforcement } \\
\left(A_{\mathrm{s}}, \mathrm{mm}^{2}\right)\end{array}$} \\
\hline & & & $\mathrm{kN}$ & $\mathrm{kN} / \mathrm{m}$ & & & \\
\hline 1 & {$[10]$} & $0.8\left(g_{\mathrm{k}}^{(1)}+q_{\mathrm{k}}\right) s L$ & 75 & 62.5 & 1.3 & $\leq \frac{l_{s}}{4.8}$ & $\begin{array}{l}1 \varnothing 20 \mathrm{~S} 240 \\
(314)\end{array}$ \\
\hline 2 & $\begin{array}{l}{[10]} \\
{[11]} \\
{[12]}\end{array}$ & $\begin{array}{l}\frac{\left(g_{k}+q_{k}\right)}{7.5} \cdot \frac{l_{r}}{5} \cdot F_{t} \\
F_{\mathrm{t}}=20+4 n_{\mathrm{s}} \text { or } 60 \mathrm{kN} / \mathrm{m}\end{array}$ & 62.69 & 51.91 & 1.97 & $\leq \frac{l_{s}}{3.2}$ & $\begin{array}{l}1 \varnothing 20 \mathrm{~S} 240 \\
(314)\end{array}$ \\
\hline 3 & $\begin{array}{l}{[12]} \\
{[8]}\end{array}$ & $\begin{array}{l}3\left(1.2 g_{\mathrm{k}}+0.5 q_{\mathrm{k}}\right) l_{\mathrm{b}} \\
3\left(g_{\mathrm{k}}+0.3 q_{\mathrm{k}}\right) l_{\mathrm{b}}\end{array}$ & 116.34 & 96.57 & 1.05 & $\leq \frac{l_{s}}{6}$ & $\begin{array}{l}1 Ø 25 \mathrm{~S} 240 \\
(491)\end{array}$ \\
\hline
\end{tabular}

Notes:

1) input data $l_{\mathrm{b}}=6.3 \mathrm{~m} ; g_{\mathrm{k}}=3.65 \mathrm{kPa} ; q_{\mathrm{k}}=1.5 \mathrm{kPa}$;

2) the value of the maximum deflection $a_{\max }=\delta_{s}=\left(g_{k}+q_{k}\right) \cdot l_{b}^{2} /\left(2 \cdot T_{j}\right)$

When determining $\alpha$ from 0 to 1.5 (according to [2]) and $F_{\mathrm{t}}$ from 24 to $60 \mathrm{kN} / \mathrm{m}$ (when the number of floors changes from 1 to 10 or more), we obtain the maximum displacement $a_{\max }=\delta_{\mathrm{s}} \leq l_{\mathrm{b}} / 1.28(!)$. The design model of [12] was obtained with $a_{\max }=\delta_{\mathrm{s}} \leq l_{\mathrm{b}} / 6$.

Basing on the analysis of the results obtained from testing the full-scale slab-to-slab joint tests carried out by PCA [2], it is implied that the catenary action will stop at an ultimate deflection greater than $\delta s=l b / 6.67$, which agrees well with the [12] requirements and other research studies. Furthermore, experimental studies [2], [18], [23] have shown that in the bar fracture failure mode the system collapses at $\delta s \approx l b / 10$. The discrepancy in the value of an ultimate vertical displacement according to the different standards [8], [10], [11] and another research provision (e.g. energy balance method) is remarkable, and standard [12] is more relaxed.

The comparison of calculation results obtained using the energy balance method and standard methods [8]-[12] (see Tab. 3) shows that the required areas of reinforcing bars used as horizontal ties are significantly different. So, when calculating according to the codes [8]-[11] $1 \varnothing 20 \mathrm{~S} 240$ is required, [12] uses 1Ø25S240 standards (see Tab. 3), while from the calculation according to the energy balance method using the dependences, " $N-w$ " is $2 \varnothing 25 \mathrm{~S} 240$.

Assuming fixed values of maximum vertical deflection (from $l_{\mathrm{b}} / 1.28$ to $l_{\mathrm{b}} / 10$ ) in the codes [8]-[12] leads to rather optimistic and relaxed results when the horizontal ties are designed.

Tab. 4 compares the values of the parametric points of the "N-w" relationship for the tie connections which were calculated according to standards [8], [9], and Tab. 5 presents robustness criteria checking results of the precast floor using the resistances $R_{\max }, R_{\mathrm{dyn}}$, assessed basing on the energy balance method.

The calculation result presented in Tab. 5 shows that checking criterion $R_{\mathrm{dyn}} \geq Q$ for horizontal ties designed according to the standards [8], [10]-[12] is not satisfied. At the same time, the designed tie connection, despite the significant plastic deformability of the rein- 
forcement S240 $\left(\varepsilon_{\text {suk }}=1.5 \cdot 10^{-2}\right)$, does not provide the a priori assumed vertical deflections without the bar rupture. A sudden failure mode of the structural system occurs. The vertical deflection of the damaged floor $a_{\max }=0.73 \mathrm{~m}$ with horizontal steel ties $1 \varnothing 20 \mathrm{~S} 240$, determined by the energy balance method considering the ultimate (rupture) steel force, turns out to be insufficient for resisting the accidental action effects. Tie forces determined by the standards [8], [10]-[12] correspond to $a_{\max }$ from $1.05 \mathrm{~m}$ to $1.968 \mathrm{~m}$, which is not realistic for this type of reinforcement (Ø20\$240).

Table 4. " $N-w$ " relationship basic parameters for analysed horizontal ties according to [7] and [24]. Source: own study

\begin{tabular}{|c|c|c|c|c|c|}
\hline \multirow{2}{*}{ № } & \multirow{2}{*}{ Reinforcement } & \multicolumn{4}{|c|}{ Parameters of the " $N-w$ " diagram } \\
\hline & & $N_{\mathrm{y}}, \mathrm{kN}$ & $N_{\mathrm{u}}, \mathrm{kN}$ & $w_{\text {end,y }}, \mathrm{mm}$ & $w_{\text {end,u }}, \mathrm{mm}$ \\
\hline 1 & $1 \varnothing 25 \mathrm{~S} 240$ & 117.84 & 153.19 & 0.492 & 38.49 \\
\hline 2 & $1 \varnothing 20 \mathrm{~S} 240$ & 75.4 & 97.97 & 0.612 & 30.8 \\
\hline
\end{tabular}

Note: " $N$-w" diagram see Fig. 5.

Table 5. Design values of resistances $R_{\max }, R_{\mathrm{dyn}}$ for the damaged system. Source: own study

\begin{tabular}{|c|c|c|c|c|c|c|c|}
\hline \multirow[b]{2}{*}{ № } & \multirow[b]{2}{*}{ Reference } & \multirow{2}{*}{$\begin{array}{l}\text { Required } \\
\text { reinforcement }\end{array}$} & \multicolumn{2}{|c|}{$\begin{array}{l}\text { Resistance of ties, } \\
\mathrm{kN}\end{array}$} & \multicolumn{2}{|c|}{$\begin{array}{l}\text { Maximum displacement } \\
a_{\max }, \mathrm{m}\end{array}$} & \multirow{2}{*}{$\begin{array}{l}\text { Criterion } \\
R_{\text {dyn }} \geq Q\end{array}$} \\
\hline & & & $R_{\max }$ & $R_{\mathrm{dyn}}$ & $\begin{array}{l}\text { according } \\
\text { to the } \\
\text { standards }^{(1)}\end{array}$ & $\begin{array}{l}\text { according to } \\
\text { the energy } \\
\text { balance }^{(2)}\end{array}$ & \\
\hline 1 & {$[10]$} & \multirow{2}{*}{$1 \varnothing 20 \mathrm{~S} 240$} & \multirow{2}{*}{23.73} & \multirow{2}{*}{11.03} & 1.3 & 0.73 & not done \\
\hline 2 & {$[10]-[12]$} & & & & 1.968 & 0.73 & not done \\
\hline 3 & {$[8],[12]$} & $1 \varnothing 25 \mathrm{~S} 240$ & 41.63 & 19.44 & 1.05 & 0.85 & not done \\
\hline 4 & according to EBM & $2 \varnothing 25 \mathrm{~S} 240$ & 60.87 & 29.52 & - & 0.61 & done \\
\hline
\end{tabular}

Note: 1) max deflection corresponding to the ultimate force in the tie calculated by the current standards; 2) max deflection by the energy balance method (EBM)

As follows from Eq. 24 obtained from the equilibrium condition of the deflected system, at a constant value of the tie force $T_{\mathrm{j}}=f_{\mathrm{yd}} \cdot A_{\mathrm{st}}$ (after yielding of steel), the global resistance of the structure linearly depends on the value of the vertical deflection $\delta_{\mathrm{s}}$. After rewriting the equation (Eq. 24), considering that $\left(g_{\mathrm{k}}+\psi_{\mathrm{i}} \cdot q_{\mathrm{k}}\right)=R_{\max }$, we obtain:

$$
R_{\max }=\frac{2 \cdot f_{y d} \cdot A_{s t}}{l_{b}^{2}} \cdot \delta_{s}
$$

For the considered case of the horizontal tie $1 \varnothing 25 \mathrm{~S} 240$ at $l_{\mathrm{b}}=6300 \mathrm{~mm}, A_{\mathrm{st}}=491 \mathrm{~mm}^{2}$ :

$$
R_{\max }=0.0059 \cdot \delta_{s, \max }
$$

\subsection{Reliability assessment of the load-bearing capacity models}

The next stage of the comparison of the proposed energy balance method (EBM) and standard methods considered in actual codes was performed basing on the reliability assessment of the damaged system with the horizontal ties designed according to provisions (requirements) of the codes and EBM. To determine failure probability, the probabilistic model for the dynamic resistance is combined with the probabilistic model for accidental load combination acting on 
the typical floor. We calculated failure probabilities for the damaged system according to the following limit state function $\mathrm{g}(\boldsymbol{X})$ :

$$
g(\boldsymbol{X})=\theta_{R} \cdot R_{d y n}-\theta_{E} \cdot(G+Q)
$$

Probabilistic models for the most important basic variables adopted in the probabilistic models for the dynamic resistance and effects of actions which are used in limit state function (Eq. 28) are listed in Tab. 6.

Table 6. Probabilistic models of basic variables for reliability analyses. Source: own study

\begin{tabular}{|c|c|c|c|c|c|c|}
\hline $\begin{array}{l}\text { Category } \\
\text { of variables }\end{array}$ & $\begin{array}{l}\text { Name of basic } \\
\text { variables }\end{array}$ & $\begin{array}{l}\text { Sym. } \\
X\end{array}$ & Dimension & Distrib. & $\begin{array}{l}\text { Mean } \\
\mu_{X}\end{array}$ & $\begin{array}{l}\text { St. dev. } \\
\sigma_{X}\end{array}$ \\
\hline \multirow{2}{*}{ Actions } & Permanent & $G$ & $\mathrm{kN}$ & $\mathrm{N}$ & $G_{\mathrm{k}}=27.59$ & $0.1 \mu_{\mathrm{G}}=2.759$ \\
\hline & Imposed & $Q$ & $\mathrm{kN}$ & GU & $0.2 Q_{\mathrm{k}}=2.268$ & $1.1 \mu_{\mathrm{Q}}=2.495$ \\
\hline \multirow{3}{*}{$\begin{array}{l}\text { Material } \\
\text { strengths }\end{array}$} & Concrete $(\mathrm{C} 20 / 25)$ & $f_{\mathrm{c}}$ & $\mathrm{MPa}$ & LN & 28 & 4,8 \\
\hline & Reinforcement (S240) & $f_{\mathrm{y}}$ & $\mathrm{MPa}$ & $\mathrm{LN}$ & 300 & 30 \\
\hline & Reinforcement (S500) & $f_{\mathrm{y}}$ & $\mathrm{MPa}$ & $\mathrm{LN}$ & 560 & 30 \\
\hline \multirow{2}{*}{$\begin{array}{l}\text { Model } \\
\text { uncertainties }\end{array}$} & Load effect factor & $\theta_{\mathrm{E}}$ & - & $\mathrm{N}$ & 1 & 0.10 \\
\hline & Resistance factor & $\theta_{\mathrm{R}}$ & - & $\mathrm{N}$ & 1 & 0.05 \\
\hline
\end{tabular}

Notes:

$\mathrm{N}$ - normal distribution; $\mathrm{LN}$ - lognormal distribution; GU - Gumbel distribution; $l_{\mathrm{s}}=6.3 \mathrm{~m} ; b_{\mathrm{s}}=1.2 \mathrm{~m}$; $g_{\mathrm{k}}=3.65 \mathrm{kPa} ; q_{\mathrm{k}}=1.5 \mathrm{kPa} ; G_{\mathrm{k}}=g_{\mathrm{k}} \times l_{\mathrm{s}} \times b_{\mathrm{s}}=27.59 \mathrm{kN} ; Q_{\mathrm{k}}=q_{\mathrm{k}} \times l_{\mathrm{s}} \times b_{\mathrm{s}}=11.34 \mathrm{kN}$

The probability density distribution functions for the different analysed design cases are shown in Fig. 6 and Fig. 7. The results of the failure probability calculations are presented in Tab. 7. Probabilistic modelling of the limit state function was performed with the use of the Monte Carlo simulation method $\left(N=10^{8}\right)$.

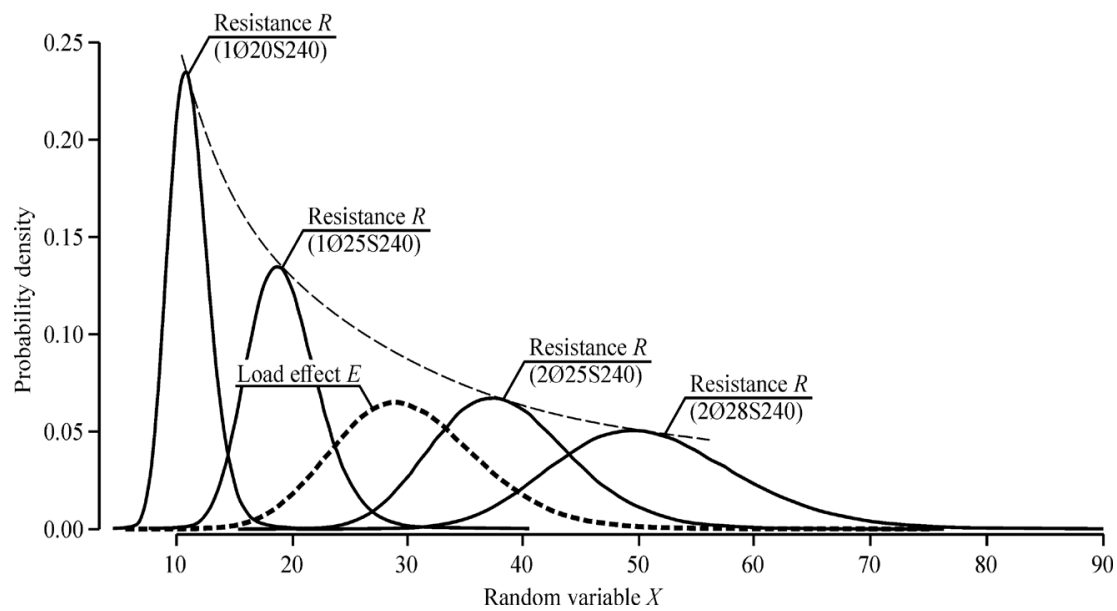

Fig. 6. Load effect $E$ and resistance $R$ as random variables for ties from reinforcement class S240. Source: own study 


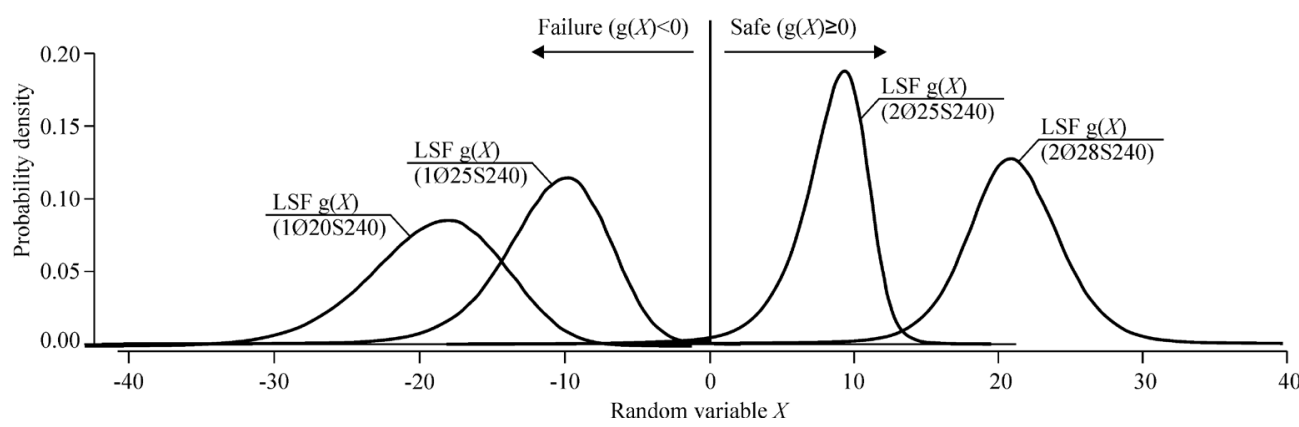

Fig. 7. Limit state function $\mathrm{g}(\boldsymbol{X})$ as random variables for ties from reinforcement class S240. Source: own study

Table 7. Results of probability simulation of performance function of damaged system with hollow-core slabs. Source: own study

\begin{tabular}{|c|c|c|c|c|c|c|c|c|c|c|}
\hline \multirow[t]{2}{*}{ № } & \multirow[t]{2}{*}{ Reference } & \multirow{2}{*}{$\begin{array}{l}\text { Req. } \\
\text { reinforcement }\end{array}$} & \multicolumn{2}{|c|}{$\begin{array}{l}\text { Resistance, } \\
R\end{array}$} & \multicolumn{2}{|c|}{$\begin{array}{l}\text { Load Effect, } \\
E\end{array}$} & \multicolumn{2}{|c|}{$\begin{array}{l}\text { Performance } \\
\text { function, } g(\boldsymbol{X})\end{array}$} & \multirow[t]{2}{*}{$p_{\mathrm{f}}(g(\boldsymbol{X})<0)$} & \multirow[t]{2}{*}{$\beta$} \\
\hline & & & mean & $\mathrm{sd}$ & mean & $\mathrm{sd}$ & mean & $\mathrm{sd}$ & & \\
\hline \multicolumn{11}{|c|}{ Ties from reinforcement of class S240 $\left(k=1.3 ; \varepsilon_{\mathrm{u}}=15 \%\right)$} \\
\hline 1 & {$[10]-[12]$} & $\begin{array}{l}1 \varnothing 20 \\
\text { S240 }\end{array}$ & 11.03 & 1.74 & & & -19.12 & 4.74 & 0.999999 & $<-4.8$ \\
\hline 2 & {$[8],[12]$} & $\begin{array}{l}1 \varnothing 25 \\
\text { S240 }\end{array}$ & 19.26 & 3.03 & 30.14 & 6.28 & -10.88 & 3.70 & 0.999971 & -4.02 \\
\hline 3 & $\begin{array}{l}\text { according } \\
\text { to EBM }\end{array}$ & $\begin{array}{l}2 \varnothing 25 \\
\text { S240 }\end{array}$ & 38.53 & 6.07 & & & 8.39 & 2.53 & 0.007649 & 2.42 \\
\hline \multicolumn{11}{|c|}{ Force-equivalent ties from reinforcement of class S500 $\left(k=1.08 ; \varepsilon_{u}=5 \%\right)$} \\
\hline 1 & {$[10]-[12]$} & $\begin{array}{l}1 \varnothing 20 \\
\text { S500 }\end{array}$ & 7.25 & 0.64 & & & -22.89 & 5.70 & 0.999999 & $<-4.8$ \\
\hline 2 & {$[8],[12]$} & $\begin{array}{l}1025 \\
\text { S500 }\end{array}$ & 12.67 & 1.12 & 30.14 & 6.28 & -17.47 & 5.28 & 0.999998 & -4.6 \\
\hline 3 & $\begin{array}{l}\text { according } \\
\text { to EBM }\end{array}$ & $\begin{array}{l}2 \varnothing 25 \\
\text { S500 }\end{array}$ & 25.34 & 2.23 & & & -4.80 & 4.33 & 0.877255 & -1.16 \\
\hline
\end{tabular}

Notes: $\mathrm{sd}-$ standard deviation; $k=f_{\mathrm{u}} / f_{\mathrm{v}} ; \beta$ is reliability index according to the Laplace function.

As can be seen from the results presented in Tab.7, only the energy balance method (EBM) in which ductility of the steel ties is considered allows to design a reliable structural system in damaged state (failure probability $p_{\mathrm{f}}(\mathrm{g}(\boldsymbol{X})<0)=0.007649$ in case 2 Ø25S240). From the analysis of the numerical results (see Tab. 7) one can conclude that the design under the actual design regulations according to codes [8], [10]-[12] is non-robust and would collapse in case of the notional column removal, even if the requirements are fulfilled according to the codes. The very close conclusions were formulated in [26] basing on own numerical investigations ("It is concluded that in case of the removal of an inner column, the original design according to the Eurocodes is very likely to fail."). We relate the main reason of this problem of the non-robust designing with the requirements of the actual codes which neglect the ductility and rotation capacity of the slab elements in the damaged system. 


\section{Brief algorithm for simplified calculation of the dynamic resistance}

As shown earlier, one of the main issues in the tie force assessment is to determine the value of deflection at which the catenary effect is mobilized. For a statically indeterminate structural system, this point can be determined using a simplified approach. As the deflection at which the catenary effect starts, point $\mathrm{a}_{0}$ of the " $F-\delta$ " relationship should be taken as shown in Fig. 8. It was assumed as the point where the nonlinear flexural response crosses with a straight-line response of the catenary effect (see Fig. 8).

a)

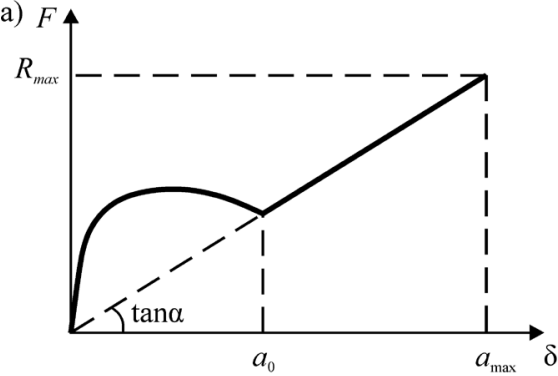

b)

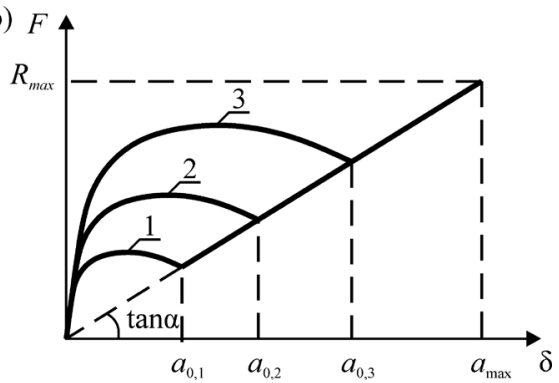

Fig. 8. For the assessment of point $a_{0}$ position. Source: own study

It should be borne in mind that the horizontal tie in the structure is either unloaded before being put into operation (when it is designed as an independent link), or has the compressive strained (when it is part of the reinforcement). The amount of horizontal tie reinforcement should be designed in such a way that a chain (membrane) effect is provided for the perception of an accidental combination of actions and that a smooth transition from a disengaging flexural plastic hinge to an engaging tensile tie is ensured. Here, the amount and ductility properties of flexural reinforcement should provide a sufficient length of the plastic deformation branch of the " $F-\delta$ " response to achieve the deflection $a_{0}$ (see Fig. 9). We should base the structural design procedure for robustness checks on ensuring a smooth and consistent transition to the mobilization of alternative loading paths.
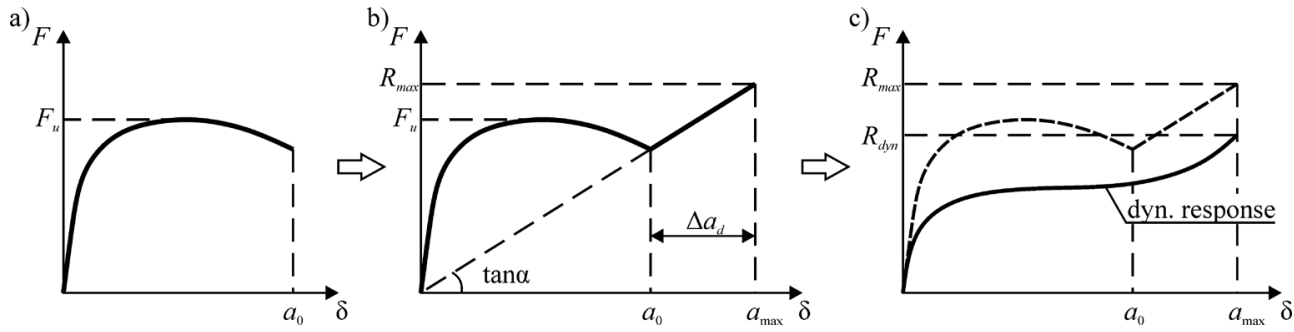

Fig. 9. Calculation steps to determination of horizontal tie system parameters : a) the response " $F-\delta$ " when a flexural plastic hinge is realized; b) common response " $F-\delta$ " for the flexural joint and horizontal tie connection; c) the dynamic response of the damaged system. Source: own study

In this case, the maximum deflection $a_{\max }$ and the resistance $R_{\max }$ should be determined basing on the energy balance equations, as shown earlier. To ensure compatibility (consist- 
ency) in the response of flexural hinges and horizontal tensile ties in statically indeterminate systems, the following procedure can be proposed:

1) a nonlinear calculation of the modified structural system is performed and the nonlinear reaction " $F-\delta$ " is determined taking into account only flexural plastic hinges behaviour (Fig. 9a). A linear reaction " $F-\delta$ " will pass through this point $\left(a_{0}\right)$, which describes, with an acceptable approximation, the operation of the horizontal tie. The slope tangent is the axial stiffness of the horizontal tie;

2) the parameters of the horizontal tie connections necessary to ensure the resistance of the accidental combination are calculated. For a given $R_{\max }$, the deformation parameters of the ties are determined, which will ensure the achievement of the maximum displacement $a_{\max }$ (Fig. 9b);

3 ) to perform complex nonlinear analysis of the damaged structural system with flexural and tension plastic hinges using computer software;

4) to calculate parametric points of a dynamic diagram and determine the global resistance of the damaged structural system (Fig. 9c), accounting for the value of the global safety factor according to [11].

\section{Conclusions}

Basing on the obtained results, the following conclusions can be drawn:

1. The proposed method for determining membrane (chain) forces based on the provisions of the energy balance method of the damaged structural system (EBM) is a promising method for calculating its maximum dynamic response. This method for the determination of the system total dynamic response can be successfully applied both in the case of simple analytical models and for complex nonlinear finite element models instead of a cumbersome nonlinear dynamic analysis (NLD) which contains a number of uncertainties (for example load history, damping coefficient, modelling error etc.).

2. Comparison of the calculation results according to the current standards [8]-[12] with the proposed energy balance method has shown that the calculation models of the codes can give an unsafe result, for example, underestimating the required cross-sectional area of horizontal ties. This is because all dependencies for calculating the tie force were based on constant values of the ultimate deflection (usually from 1/6 to $1 / 10$ of the span), without checking the ultimate deformability of horizontal ties. As follows from the performed analysis, with the unchanged value of the accidental combination of actions, the calculated tie force (for which its cross-section is selected) will change in inverse proportion to the deflection. The approach adopted in the standards [8]-[12] can lead to unrealistic results when the adopted reinforcement in horizontal tie cannot ensure the achievement of the a priori maximum deflection due to insufficient deformability. The model included in [12], in which the constant deflection of $1 / 10$ span is used to derive the design equations, is most similar to the solutions based on the energy balance. Changes should be made to the current standards [8]-[10] in terms of the application of methods based on the energy balance of the system for the design of horizontal ties.

3. Taking into account a number of assumptions made in the formulation of the basic provisions of the method based on the energy approach, it is necessary to perform 
a statistical analysis of the uncertainty modelling basing on the results of experimental studies, but not on the results of dynamic calculations of the finite element model as done in [23].

\section{References}

[1] Adam J.M., Parisi F., Sagaseta J.,Lu X., "Research and practice on progressive collapse and robustness of building structures in the 21st century", Engineering Structures, vol. 173, (2018), pp. 122-149. https://doi.org/10.1016/j.engstruct.2018.06.082

[2] Tohidi M., Effect of floor-to-floor joint design on the robustness of precast concrete cross wall buildings. PhD dissertation, University of Birmingham, UK, 2015.

[3] El-Tawil S., Li H. and Kunnath S., "Computational simulation of gravity-induced progressive collapse of steel-frame buildings: Current trends and future research needs", Journal of Structural Engineering, vol. 140, no. 8, (2014), A2513001. https://doi.org 10.1061/(ASCE) ST.1943-541X.0000897

[4] Byfield M., Mudalige W., Morison C. and Stoddart E., "A review of progressive collapse research and regulations", Proceedings of the Institution of Civil Engineers-Structures and Buildings, vol. 167 , no. 8 , (2014), pp. 447-456.

[5] Fang Z.X. and Fan H.T., "Redundancy of structural systems in the context of structural safety", Procedia engineering, vol. 14, (2011), pp. 2172-2178. https://doi.org/10.1016/j.proeng.2011.07.273

[6] Folić R., "Structural Robustness of monolithic and precast RC building”, in First Scientific-applied Conference with International Participation Reinforced Concrete and Masonry Structures-Theory and Practice, Sofia, 2015.

[7] fib Bulletin 43. Structural connections for precast concrete buildings. Guide to good practice, 2008. https://doi.org 10.35789/fib.BULL.0043

[8] SP 5.03.01-2020. Concrete and reinforced concrete structures. Minsk, Belarus, 2020. (In Russian)

[9] SN 2.01.01-2019. Basis of structural design. Minsk, Belarus, 2020. (In Russian)

[10] EN 1991-1-7. Eurocode 1-Actions on structures - Part 1-7: General actions - Accidental actions, 2006.

[11] BS 8110-1. The structural use of concrete in building - Part 1: Code of practice for design and construction, 1997.

[12] Department of Defense (DoD) Unified Facilities Criteria (UFC-04-023-03). Design Building to Resist Progressive Collapse. Washington, D.C., 2005

[13] MC2010. fib Model Code for Concrete Structures, International Federation for Structural Concrete (fib), 2010.

[14] ISO 2394:2015. General principles on reliability of structures. International Standard, 2015.

[15] Qian K. and Li B., "Research advances in design of structures to resist progressive collapse", Journal of Performance of Constructed Facilities, vol. 29, no. 5, (2015), B4014007. https://doi. org10.1061/(ASCE)CF.1943-5509.0000698

[16] Tur A. and Tur V., "Reliability Approaches to Modelling of the Nonlinear Pseudo-Static Response of RC-structural Systems in Accidental Design Situations", Journal of Sustainable Architecture and Civil Engineering, vol. 22, no. 1, (2018), pp. 76-87.

[17] Herraiz B., Vogel T. and Russell J., "Energy-based method for sudden column failure scenarios: theoretical, numerical and experimental analysis", in IABSE Workshop Helsinki 2015: Safety, Robustness and Condition Assessment of Structures. Report, International Association for Bridge and Structural Engineering IABSE, 2015, pp. 70-77. https://doi.org/10.3929/ethz-a-010389549 
[18] Izzuddin B.A., Vlassis A.G., Elghazouli A.Y. and Nethercot D.A., "Progressive collapse of multi-storey buildings due to sudden column loss - Part I: Simplified assessment framework", Engineering structures, vol. 30, no. 5, (2008), pp. 1308-1318. https://doi.org/10.1016/j.engstruct.2007.07.011

[19] Vlassis A.G., Izzuddin B.A., Elghazouli A.Y. and Nethercot D.A., "Progressive collapse of multi-storey buildings due to sudden column loss - Part II: Application", Engineering Structure, vol. 30, no. 5, (2008), pp. 1424-1438. https://doi.org/10.1016/j.engstruct.2007.08.011

[20] ASCE. Minimum design loads for buildings and other structures. American Society of Civil Engineers, 2013.

[21] Tur V., Tur A., Lizahub A. and Derechennik S., "Accidental actions values and combinations for key-elements checking”, in E3S Web of Conferences, vol. 212, EDP Sciences, 2020. https://doi. org 10.1051/e3sconf/202021202019

[22] Van Coile R., Hopkin D., Elhami Khorasani N., Lange D. and Gernay T., "Permanent and live load model for probabilistic structural fire analysis: a review", in 3rd International Conference on Structural Safety under Fire and Blast Loading, Brunel University, London, 2019, 2nd $-4^{\text {th }}$ September 2019.

[23] Ding L., Van Coile R., Botte W. and Caspeele R., "Quantification of model uncertainties of the energy-based method for dynamic column removal scenarios", Engineering Structures, vol. 237, (2021), pp. 112057. https://doi.org/10.1016/j.engstruct.2021.112057

[24] fib Bulletin 72. Bond and anchorage of embedded reinforcement: Background to the fib Model Code for Concrete Structures 2010. Technical report. fib-Fédération internationale du béton, 2014. https://doi.org 10.35789/fib.BULL.0072

[25] Tur A.V., Petsold T.M., Tsimbarevich T.A., "Experimental research of the robustness of disk of overlapping from the hollow core slabs with removing the carrier element", Bulletin of the Brest State Technical University, vol. 1, (2018), pp. 104-109.

[26] Droogné, D., Caspeele, R., Taerwe, L., and Herraiz, B., "Parametric study and reliability-based evaluation of alternate load path design in reinforced concrete slabs", In $39^{\text {th }}$ IABSE Symposium-Engineering the Future, (2017), pp. 1106-1113. IABSE. 
